\title{
DA ESCOLA, DO ESCOLAR, DA INCLUSÃO
}

\author{
Carla Mercês Jatobá Ferreira (UFOP)* \\ https://orcid.org/0000-0001-9888-7743 \\ Angela Resende Vorcaro (UFMG)** \\ https://orcid.org/0000-0002-6538-8646
}

\section{RESUMO}

0 presente artigo tem como principal objetivo discutir aspectos conceituais e estruturais da escola, do escolar e da inclusão. Sua construção está disposta em três seções. Na primeira, discute-se elementos da escola pelo viés estrutural, abordando as noções de forma e organização escolar e sua disseminação nas instituições educativas modernas. Em continuidade com a seção anterior, discorre-se sobre a noção/lugar do escolar atribuído às crianças na sua inserção na escola e as possíveis transformações advindas da condição de escolar, considerando a ruptura com formas anteriores de socialização para a infância. Na última seção, contempla-se a inclusão escolar enfatizando aspectos políticos como também mecanismos de resistências advindos na tentativa de fazer cumprir as determinações legais no cotidiano das escolas. Aborda-se manifestações por parte dos atores envolvidos com o processo de inclusão educacional considerando que processos de formação reativa ao trabalho educativo com crianças em situação de deficiência buscam se apoiar nas estruturas da forma e organização escolares.

Palavras-chave: Escola. Escolar. Inclusão. Forma e estrutura escolares.

\section{ABSTRACT}

\section{OF THE SCHOOL, OF THE SCHOOLCHILDREN, OF THE INCLUSION}

The main objective of this article is to discuss conceptual and structural aspects of the School, Schoolchildren and Inclusion. The text is constructed in three sections. In the first, elements of the school are discussed from a structural perspective, addressing the notions of school form and organization and their dissemination in modern educational institutions. Continuing with the previous section, we present and problematize the notion/place of schoolchildren assigned to children in their insertion in school and the possible changes arising from this condition, seen as a break with previous forms of socialization in childhood. In the last section, school inclusion is addressed, emphasizing political aspects as well as mechanisms of resistance arising from the attempt to enforce legal determinations in the daily life of schools. Manifestations on

* Doutora em Educação pela Universidade de São Paulo (USP). Professora do Programa de Pós-Graduação em Educação da Universidade Federal de Ouro Preto (PPGE/UFOP). E-mail: carlajatobaferreira@gmail.com

** Doutora em Psicologia Clínica pela Pontifícia Universidade Católica de São Paulo (PUC-SP). Professora do Programa de PósGraduação em Psicologia da Universidade Federal de Minas Gerais (UFMG). E-mail: angelavorcaro@uol.com.br 
the part of the actors involved in the process of educational inclusion are also confronted, considering that reactive processes to educational work with children in situations of disability seek to rely on the structures of school form and organization.

Keywords: School. Schoolchildren. Inclusion. School form and structure.

\section{RESUMEN}

\section{DE LA ESCUELA, DEL ESCOLAR, DE LA INCLUSIÓN}

El objetivo principal de este artículo es discutir aspectos conceptuales y estructurales de la Escuela, lo Escolar y la Inclusión. Su construcción se organiza em ter tramos. Em el primero se discutem elementos de la escuela a través Del enfoque estructural, abordando las nociones de forma y organización escolar y su difusión en las instituciones educativas modernas. Continuando com el apartado anterior, se comenta la noción/ lugar de lós escolares asignados a los niños em su inserción en la escuela y los posibles cambios derivados de la condición de los escolares ante la ruptura con formas previas de socialización para la infancia. En el último apartado se enfatiza la inclusión escolar, enfatizando tanto los aspectos políticos como los mecanismos de resistencia que surgen del intento de hacer cumplir las determinaciones legales em la vida cotidiana de las escuelas. Se abordan las manifestaciones de los actores involucrados em el proceso de inclusión educativa, considerando que los procesos de formación reactiva al trabajo educativo com ninõs em situación de discapacidad buscan apoyarse em las estructuras de forma y organización escolar.

Palabras clave: Escuela. Escolar. Inclusión. Forma y estructura de la escuela.

\section{Introdução}

A escola é uma organização complexa e sólida, que atravessa e responde a civilização. Ao longo da sua presença nos agrupamentos humanos, as instituições escolares foram adquirindo atributos diferenciados relativos às demandas surgidas durante sua existência, assim como ao investimento que cada nação destina para a formação humana da sua população. Afinal, a escola moderna tem sua origem vinculada ao nascimento do Estado. Formar cidadãos foi um dos seus objetivos primevos.

Milner (2009), no seu ensaio De l'école, ${ }^{1}$ assinala que falar sobre a existência da escola é dizer sobre a existência de saberes transmitidos por um corpo especializado em um lugar

1 Traduzimos como Da Escola. Este ensaio é que nos inspirou para nomear o presente artigo. A tradução é das autoras, tanto para esta obra como para as demais que estão referenciadas nas páginas seguintes. específico. Esse autor destaca que abordar a escola implica explicitar quatro determinações essenciais: a primeira delas seria os saberes; a segunda, dos saberes passiveis de transmissão; a terceira seria sobre os especialistas encarregados de transmitir os saberes; e a quarta situa a escola como uma instituição reconhecida com a função de "reunir presencialmente, de uma maneira organizada, os especialistas que transmitem e os sujeitos para quem se transmite" (MILNER, 2009, p. 13). Por conseguinte, ao se anunciar que a escola existe, anunciase, simultaneamente, a existência das quatro determinações citadas, e em uma dimensão inversa, ou seja, para se negar a existência da escola, bastaria que uma dessas determinações deixe de existir.

Milner (2009) considera a permanente possibilidade de, à escola, acrescentar-se outras 
determinações àquelas citadas como essenciais. Contudo esse autor ressalta a necessidade de considerá-las como secundárias, como acréscimos, pois pretender transformá-las em benefícios maiores significa "renunciar às determinações essenciais. É desejar o fim da escola" (MILNER, 2009, p. 14).

Contudo, a escola moderna, ao abrir suas portas às crianças do povo, logo foi adquirindo novas significações. Ao acolhê-las, no âmbito do seu modelo institucional, "impacientou-se", e logo inventou dispositivos para afastá-las (BINET; SIMON, 1907, 1909). Há saberes que não são para todos; atitudes de desconfiança e discriminatórias foram instaladas através de processos classificatórios dando lugar na historiografia da instituição escolar à noção de fracasso escolar (PATTO, 1993; PINELL; ZAFIROPOULOS, 1983; SOUZA, 1998). 0 tema atravessou séculos e à escola somam-se novos significantes que dizem da sua ineficácia diante da função de educar a todos. Contudo, as reações aos movimentos excludentes que expulsariam as crianças das instituições escolares não tardariam a se manifestar uma vez que discussões sobre a educação das crianças consideradas "anormais", "idiotas", "deficientes", "excepcionais" ocorriam desde a segunda metade do século XIX (HUGON; GATEAUX; VIAL, 1984; MUEL, 1975). A educação dos inadaptados ao sistema educativo regular vai se configurando como um campo de lutas e disputas e seu percurso histórico comporta modelos diversos, desde as escolas especiais às escolas inclusivas (JANNUZI, 2006; MAZZOTTA, 2005; MENDES, 2010). Entretanto, como um traço que permanece nas lutas dos grupos historicamente colocados na posição de excluídos, ao modelo inclusivo já se acrescem efeitos de segregação. Tornar a educação inclusiva (FÁVERO; FERREIRA, 2009) denota não ser apenas um exercício de cumprir prerrogativas legais e dotar as escolas dos equipamentos tecnológicos necessários, como têm assinalado diversos pesquisadores.

Assim, no mesmo movimento em que os ditos deficientes, delinquentes, doentes e loucos explicitam a impotência da escola para cumprir prerrogativas constitucionais democráticas da escola para todos os cidadãos, testemunham a elevação exponencial da exclusão que ela pode inserir em seu território próprio. A despeito de estarem matriculados na escola por força de lei, não conseguem se tornar alunos; quando nomeados, são reduzidos à terminologia científica do "mal que os acomete" ou crianças/jovens da inclusão. Assim adjetivados, não ganham a legitimidade para se inserir no terreno do aprender, tornam-se ilegítimos, mesmo que tolerados no campo escolar.

Nossa inquietação com a condição das crianças em situação de deficiência ${ }^{2}$, ou, como nomeadas pela Política Nacional de Educação Especial na Perspectiva Inclusiva (PNEEPEI) (BRASIL, 2008), alunos público-alvo da educação inclusiva (PAEE), nos conduz às reflexões que abordamos no presente artigo. Sua construção está disposta em três seções, quando, inicialmente, buscamos discutir a instituição escolar pelo viés estrutural abordando suas noções de forma e organização escolar; em seguida discutimos a noção/lugar do escolar atribuído à criança na sua inserção na escola para, então, finalizarmos tratando alguns aspectos da inclusão escolar, assim como os mecanismos de resistências advindos na tentativa de fazer cumprir as determinações legais no cotidiano das escolas. Neste último tópico discorremos sobre tais manifestações por parte dos atores envolvidos com o processo de inclusão educacional, conjuntamente aos preceitos apontados nas seções anteriores.

\section{Da Escola}

Dizer que a escola é moderna é dizer de sua relação com o tempo. É situar sua construção e sua emergência. Como assevera Rui Canário (2005), que aqui nos referencia, nada é intemporal no domínio escolar.

2 Conhecemos esta expressão com Plaisance. Ver Neves, Rahme e Ferreira (2019). 
Não ignoramos a importância das origens históricas da instituição escolar, já contempladas em vasta bibliografia tanto no nosso país (FREITAS; BICCAS, 2009; NASCIMENTO et al., 2007), como no âmbito internacional (CAMBI, 1999; LELIÈVRE, 1991; MANACORDA, 1996; PINTASSILGO et al., 2007). Não temos o intuito de voltar a essas origens, aqui presentes como cenário necessário. Entretanto, focalizamos nossa discussão no destaque à combinação dos termos: instituição educativa.

Freud (2010, p. 48) explicita a imprescindível relação da civilização com as instituições: "civilização designa a inteira soma das realizações e instituições que afastam a nossa vida daquela de nossos antepassados animais e que servem para dois fins: a proteção do homem contra a natureza e a regulamentação dos vínculos dos homens entre si", além de nos advertir sobre a necessidade das instituições "para regulamentar as relações entre os indivíduos e, em especial, a distribuição dos bens obteníveis" (FREUD, 2014, p. 233). Balizando e provendo meios de controle pulsional humano, as instituições visam a garantir que possamos viver juntos.

Se, nas assertivas de Freud (2014), podemos reconhecer certa sinonímia que inevitavelmente aproxima instituição e educação, Dermeval Saviani (2005) ressalta que, mesmo apresentando uma diversidade de significados, a palavra instituição retém a concepção de algo que foi constituído e organizado pelo homem e que

[...] além de ser criada pelo homem, a instituição se apresenta como uma estrutura material que é constituída para atender a determinada necessidade humana, mas não a qualquer necessidade. Trata-se de necessidade de caráter permanente. Por isto a instituição é criada para permanecer. Se observarmos mais atentamente o processo de produção das instituições, notaremos que nenhuma delas é posta em função de alguma necessidade transitória, como uma coisa passageira que satisfeita a necessidade que a justificou, é desfeita. Para necessidades transitórias não se faz mister criar instituições. (SAVIANI, 2005, p. 28).
Vale ressaltar que o autor nos esclarece com respeito ao caráter permanente das instituições, ou seja, que para serem permanentes estas também devem estar inscritas na transitoriedade das criações humanas. Deste modo, sua existência é determinada historicamente e não cronologicamente.

Abordemos então a escola, laica e racionalista, recortando-a, através de alguns dos seus elementos constitutivos responsáveis pela maneira como a conhecemos na atualidade. Partamos de uma definição sobre a escola

[...] uma invenção histórica, contemporânea da dupla revolução industrial e liberal que baliza o início da modernidade e que introduziu, como novidades, o aparecimento de uma instância educativa especializada que separa o aprender do fazer; a criação de uma relação social inédita, a relação pedagógica no quadro da classe, superando a relação dual entre o mestre e o aluno; uma nova forma de socialização (escolar) que progressivamente viria a tornar-se hegemônica. (CANÁRIO, 2005, p. 61).

A escola, já secular, vem atravessando o tempo. Como instituição moderna provoca novos modos de socialização ao inventar a relação pedagógica. A invenção é datada historicamente e aporta com ela a noção de infância e a pedagogia como ciência. A relação pedagógica marca sua especificidade: acontecer em um lugar específico e com tempo diferenciado das demais atividades sociais (CANÁRIO, 2005, 2008; MAULINI, PERRENOUD, 2005; VINCENT; LAHIRE; THIN, 2001). Será a partir destas especificidades que discorreremos.

Aprender passa a ser uma ação delimitada pelo tempo e espaço institucionais. A escola, ao mesmo tempo em que inaugura novos formatos para o aprender, também delimita a ação educativa. Há forma e organização que lhes são próprias articuladas à estrutura de controle institucional. Se, no Ancien Règime crianças adquiriam os saberes nos espaços de convivência por "ver-fazer" e "ouvir-dizer", a escola moderna originaria práticas distintas (VINCENT; LAHIRE; THIN, 2001). 
Discutindo as "ordens e desordens na escola”, Anne Barrère e Nicolas Sembel (2006, p. 96) ressaltam o caráter de estabilidade promovido pela "forma escolar" definindo-a como

[...] uma configuração particular, surgida na França urbana do fim do século XII e sempre viva na atualidade, apesar dos desvios e - talvez - de uma crise. Essa configuração corresponde à articulação de uma relação pedagógica, de uma relação no espaço e no tempo, enfim, de uma relação com o saber indissociável da relação com a escrita.

A novidade da relação pedagógica consistia em circunscrever a infância em um espaço institucional regrado pela pedagogia das horas, do exercício e da repetição. A forma escolar ${ }^{3}$ define seus contornos e surge, pretensamente, como o modelo para a aprendizagem escolar. Um professor seria o responsável por muitos alunos - por uma classe. Aprender e ensinar se delineariam como processos marcados pela ideia da homogeneidade, e como traço persistente, não haveria espaços para considerar as experiências singulares dos alunos. A difusão do projeto educativo se estende amplamente, "abarcando seja a mentalidade seja os comportamentos" (CAMBI, 1999, p. 203).

A “organização" escolar, em seu surgimento, é também uma novidade. A simultaneidade do ato de ensinar, a concepção dos espaços, a delimitação do tempo e o agrupamento dos alunos foram determinantes no desenho escolar, e sua estrutura foi moldada de forma tão eficaz que, como aponta Canário (2005), tornou-se quase invisível.

O "tempo" escolar, suspenso da temporalidade cotidiana, é cuidadosamente delimitado pelos "espaços" onde o controle, a previsão e a codificação são as operações organizadoras. Neste delineamento não se permite espaços

3 Utilizamos também a forma escolar na acepção de Vincent, Lahire e Thin (2001, p. 9) quando dizem da análise sócio-histórica do termo e ressaltam que "falar de forma escolar, é portanto, pesquisar o que faz a unidade de uma configuração histórica particular, surgida em determinadas formações sociais, em certa época, e ao mesmo tempo que outras transformações, através de um procedimento tanto descritivo quanto compreensivo". para os imprevistos e o acaso. A "forma” e a "organização" escolares são dimensões características da escola em sua temporalidade, quando, "não sem dificuldades, um modo de socialização escolar se impôs a outros modos de socialização" (VINCENT; LAHIRE; THIN, 2001, p. 11). Juntas estruturam e ditam como ordenar a presença das crianças na escola e como desenvolver as modalidades do trabalho escolar.

Num espaço fechado e totalmente ordenado para a realização, por cada um, de seus deveres, num tempo cuidadosamente regulado que não pode deixar nenhum espaço a um movimento imprevisto, cada um submete sua atividade aos 'princípios' ou regras que a regem. (VINCENT; LAHIRE; THIN, 2001, p. 15, grifo do autor).

A regulação do tempo envolta pela contínua disciplina rege o trabalho escolar e o tempo de permanência na escola é insistentemente cronometrado pela divisão, organização e tentativa de evitar o desperdício, como se a sucessão dos ritos escolares aprisionasse o tempo, imprimindo nas crianças a ideologia moderna da produtividade. Franco Cambi (1999, p. 206) assinala esta marca ao considerar que "toda a vida escolar é uma sucessão de obrigações produtivas organizadas em unidades temporais".

A ordem, o tempo e o receio do seu desperdício, atrelados à ideia da homogeneidade das idades, são os contornos aos quais as crianças, modernamente escolares, estariam submetidas. Para a realização das atividades escolares, seus corpos deveriam adotar posturas recomendadas, desde o sentar à forma de segurar o lápis, perfilando a ideia disciplinar do domínio e controle do corpo: as práticas escolares demandam utensílios específicos, ou seja, o uso de objetos pertencentes ao universo escolar, como também das cartilhas, dispositivos que buscam "instruir e moralizar a criança" (BECCHI, 1998, p. 186).

A forma escolar tradicional reveste a escola de uma estabilidade presa ao tempo. Marcada pela organização das práticas educativas que se apresentam insistentemente através dos 
rituais, da rotina, da divisão de tarefas como estratégias garantidoras da presença do passado nas instituições escolares tanto quanto buscam reduzir as incertezas do futuro. Este conjunto de elementos, associado às formas de organização do conhecimento e modos de autorizar o acesso das crianças ao mesmo, assim como as modalidades avaliativas, "[...] têm sido identificados como práticas que obedecem a um conjunto de regras sumariamente estáveis que constituem o que alguns autores têm denominado de gramática escolar ou componentes duros do formato escolar" (BAQUERO; DIKER; FRIGERIO, 2009, p. 8).

Assim, a "gramática escolar" dita os modos de inserção no universo escolar. Somada a um conjunto específico de modos de comportamento disciplinar, produziriam efeitos de socialização na criança que, desta forma, se transformaria no "escolar".

\section{Do Escolar}

O termo "escolar" é definido pelo Dicionário UNESP do Português Contemporâneo (BORBA, 2004, p. 526) como um adjetivo "referente a escola"; "de escola"; "usado na escola"; "de estudante"; "de ensino"; "da escola"; "que se dá na escola". No Dicionário Houaiss da Língua Portuguesa (INSTITUTO ANTONIO HOUAISS, 2012, p. 313), escolar é um adjetivo que apresenta três significações distintas: a primeira significando "relativo a escola", a segunda, "utilizado na escola", e a terceira, "estudante". Para o dicionário de Língua Francesa Le Nouveau Petit Robert (ROBERT, 1996, p. 711, tradução nossa), écolier significa "aluno, estudante; criança que frequenta a escola maternal ou primária, seguida das pequenas classes de um colégio; colegial, aluno".

Estamos particularmente interessadas na acepção "estudante" presente nas três referências acima citadas. A acepção nos conduz à escola. A escola (antes da disseminação dos berçários e creches) significou para a criança um universo diferenciado dos até então conhe- cidos possibilitados pela vivência infantil. A criança que chega à escola está envolta em uma rede de significados traduzidos pelos procedimentos e técnicas pedagógicas. A pedagogia dará seu contorno a esta criança, agora, escolar. Um conjunto de elementos foi disposto e traduzia as novas formas de enxergar a criança. Desde a imponente arquitetura das escolas do século XIX ao conjunto de leis que obrigavam as crianças a frequentá-las, se constituíram diversas concepções sobre a infância com a persistente recomendação de cultivar suas capacidades. Esta concepção é destacada por Egle Becchi (1998) quando assinala o conjunto de ideias articuladas em torno da criança e seu desenvolvimento e sua aprendizagem da leitura, da escrita, da matemática e das ciências naturais, entre outras, e como também instruí -la no cumprimento

[...] dos seus deveres de cidadã, e isto não seria o aspecto menos relevante, desenvolver seu corpo para a ginástica, tudo isto é objeto de reflexões, de articulação de programas, da colocação em prática de técnicas pedagógicas aperfeiçoadas, ou melhor, adaptadas às capacidades da criança e ao seu desenvolvimento, melhor controlado pelo professor. (BECCHI, 1998, p. 193).

0 crivo pedagógico invadia a infância, originando uma disposição reducionista para enxergá-la da qual nunca mais foi possível se libertar. Com a pedagogia, a criança não seria mais a mesma (LAJONQUIÈRE, 1999). A supremacia do crivo "escolar" foi disseminada de tal maneira que provoca alterações nas formas de socialização e de aprendizagem, e como sublinha Rui Canário (2005, p. 66), "induzindo uma pedagogização das relações sociais, e desapossando alguns grupos sociais das suas competências e prerrogativas".

O processo de fazer da criança um "escolar" não ocorreu sem conflitos. 0 enquadramento institucional da escola moderna provocava a fuga e o absenteísmo. A rigidez da disciplina assegurada pela aplicação de castigos físicos provocava nas crianças o desprezo pelo universo da escola e seu sistema pedagógico 
(BECCHI, 1998). Exemplos da reação de fuga, do tênue interesse pelo mundo escolar e dos castigos aplicados pelos professores aos alunos encontramos na literatura brasileira no Conto de Escola, de Machado de Assis (2012); realçamos o excerto da narrativa quando o menino, protagonista do Conto, ao sair de sua casa a caminho da escola, decide seguir outro rumo:

Na rua encontrei uma companhia do batalhão de fuzileiros, tambor à frente, rufando. Não podia ouvir isto quieto. Os soldados vinham batendo o pé rápido, igual, direita, esquerda, ao som do rufo; vinham, passaram por mim, e foram andando. Eu senti uma comichão nos pés, e tive o ímpeto de ir atrás deles. Já lhes disse: o dia estava lindo, e depois o tambor... olhei para um lado; afinal, não sei como foi, entrei a marchar também ao som do rufo, creio que cantarolando alguma coisa: Rato na casaca... Não fui à escola, acompanhei os fuzileiros, depois enfiei pela Saúde e acabei na Praia da Gamboa. (ASSIS, 2012, p. 133).

Estar na escola significa introduzir-se em um território demarcado por uma gramática singular onde tempo e espaço possuem contornos próprios. Codificar os tempos, ler os espaços e rotas de circulação, distinguir onde se deve estar diante das demarcações do tempo são atributos do processo de reconhecimento do universo escolar. 0 tradicionalismo pedagógico não ignora esses atributos. Saber se reconhecer nessa dinâmica e dominar a leitura dos tempos escolares não são conquistas fortuitas mas, sim, traduzem um rito de passagem, de, na capacidade de ler os códigos escolares, se deixar conduzir. É o que ilustra uma lembrança da nossa prática docente com crianças pequenas: nosso aluno, ao cessar as lágrimas que lhe acompanharam durante as duas primeiras semanas de frequência à escola, passou a antecipar os elementos da rotina. Quando se aproximava, nos dizia com a voz baixinha, quase um sussurro "depois a gente lancha... e depois, é hora do parquinho". Assim, ele permaneceu durante algumas semanas ocupado em traduzir o novo espaço e sua rotina, para então poder dispensar essas condutas e, pouco a pouco, advir como um menininho faceiro, participativo e cheio de perguntas pelos temas dos nossos projetos e vivências em sala.

Acreditamos que dominar o rito de passagem é ter o entendimento do funcionamento escolar e, assim, poder se situar neste espaço como um aluno. Consideramos que há um ponto de enredamento dos dois lugares. 0 scholar entrelaça-se ao alumnu. A operação tem sua complexidade e, assim, provoca efeitos subjetivos, como se a partir deste enredamento franquear-se-ia aberturas para se adentrar na cadeia da transmissão dos saberes. Interessa sublinhar que no Dicionário Etimológico da Língua Portuguesa, de Antenor Nascentes (1955), "aluno" é termo originário do latim alumnu, sendo definido por criança que se dá para criar. Assim, o étimo explicita o caráter de cessão dos direitos, poderes e responsabilidades inicialmente parentais para uma outra instância, desta vez social.

A construção histórica da escola e sua exterioridade - relativamente ao mundo social - conduziram ao aparecimento de uma nova categoria social, o aluno, como efeito de transformação da criança e sua adaptação às regras escolares (CANÁRIO, 2005).

\section{Da Inclusão}

As políticas para a educação inclusiva têm ocupado o discurso das conquistas democráticas desde as últimas décadas do século XX. Concebidas como proposições para combater tanto as desigualdades socioeconômicas como aquelas referentes ao acesso à formação escolar, procura, através do seu ordenamento jurídico, garantir a matrícula escolar de crianças que, até então, por razões diversas, viveram apartadas da escola.

Ainscow (2009), em seu ensaio Tornar a educação inclusiva: como essa tarefa deve ser conceituada?, aborda o tema da inclusão educacional como questão desafiadora para o sistema escolar, ressaltando o crescente interesse por suas propostas em diversos 
países; assim como a particularidade do terreno discursivo ao contemplar diversas questões perante a necessidade de ações para que avanços políticos e educativos ocorram. Sublinhando a condição da educação como um direito humano essencial que em sua vertente inclusiva teria como objetivo eliminar formas de exclusão que vetam o acesso à escola para milhares de pessoas no mundo, esse autor critica os sistemas educativos anteriores (integração), assinalando o caráter segregador de suas práticas especiais ambientadas nas escolas regulares. 0 ponto crítico assinalado por Ainscow (2009) é referente ao fato de que a presença dos alunos considerados especiais nas escolas comuns não provocou mudanças na organização escolar. Tal constatação é distinguida como grande empecilho ao desenvolvimento da educação inclusiva.

Vale ressaltar que Ainscow (2009) enfatiza a importância de revisão na organização escolar com vistas a contemplar a diversidade dos alunos. Algumas atitudes, tais como a análise das dificuldades vivenciadas por estes, como também práticas docentes colaborativas, são propostas por esse autor enquanto posturas orientadoras da transformação dos sistemas educativos em uma direção inclusiva.

Refletindo sobre o título do ensaio, Tornar a educação inclusiva, e retornando ao Dicionário Etimológico da Língua Portuguesa, de Antenor Nascentes (1955), "tornar" vem do latim tornare, significando trabalhar no torno, calcado no tornos, giro; para o Dicionário UNESP do Português Contemporâneo (BORBA, 2004), "tornar" como verbo transitivo acrescido de "a", como o título acima, significa voltar; retornar; regressar; como também voltar a um estado ou condição anteriores; o "a" acrescido de predicado, fazer vir a ser. Essas múltiplas acepções aqui destacadas nos encaminham para algumas digressões. A origem leva ao trabalhar no "torno" - às possibilidades de modelar, ou seja, de produzir acabamentos. Como verbo transitivo remete à ideia de retorno e também a um porvir.
Os paradoxais sentidos permitem duas possibilidades de significância: a primeira, diante da ideia de retorno, nos conduz ao De l'école, quando Jean-Claude Milner (2009) declara que qualquer outra finalidade que venha a se associar às quatro essenciais podem ser consideradas como secundárias, ou supérfluas, e, desta forma, a educação inclusiva seria uma redundância ao próprio objetivo da escola moderna de educar a todos. Por outro lado, o adjetivo "inclusiva" acrescido à educação, indica a distância persistente na escola moderna em relação a seu objetivo primeiro - o "para todos" teria insistido apenas como linha no horizonte não realizada, a que a noção de inclusão poderia aceder. Para a segunda possibilidade, "fazer vir a ser", associamo-la ao sentido etimológico, ao trabalho de moldar, de dar acabamento - e assim, conduzindo a uma ideia de construção.

Considerando a educação inclusiva como uma construção, constatamos que as determinações propostas pelas políticas públicas geraram alterações significativas na cena escolar. É o que testemunha o movimento de crianças com a marca da diferença circulando no interior das escolas, assim como a presença de novos profissionais com suas especialidades situadas no campo da educação especial e com funções que abrangem desde a locomoção ao campo das aprendizagens até o amortecimento dos efeitos da turbulência causada pela presença das novas crianças no âmbito escolar. Como acentuam Thomazet e Mérini (2015), a escola inclusiva se apresenta como um "objeto de fronteiras". Os novos sujeitos, mesmo que timidamente, dispõem suas marcas na cena escolar (FERREIRA; LOPES, 2016; RAHME, 2014) mesmo diante dos efeitos de perturbação e incômodo que a letra da lei viria a provocar. 0 discurso sobre a inclusão atingiria outros espaços sociais como os lares das crianças, os espaços de lazer, instituições religiosas, entre outros, demarcando o campo das políticas afinadas com aquilo que é considerado politicamente correto e a demanda para que a escola, como instituição, consiga abarcar 
todas as crianças, indistintamente (CAVALLARI, 2014; FREITAS, 2011).

Transcorrida mais de uma década da promulgação do marco político brasileiro para uma política educacional inclusiva - A Política Nacional de Educação Especial na Perspectiva da Educação Inclusiva (PNEEPEI) -, a educação pública escolar para crianças e jovens em situação de deficiência permanece como um tema merecedor de discussões.

A PNEEPEI é considerada um marco distintivo para a educação brasileira, pois

[...] modifica a orientação relativa à oferta dos serviços especializados, que passam a ser complementares e/ou suplementares à educação comum, e não mais substitutivos. Essa orientação afeta diretamente o fluxo do percurso escolar dos estudantes com deficiência e o modo de oferta do atendimento educacional especializado a esse grupo (RAHME; FERREIRA; NEVES, 2019, p. 2)

A respeito da introdução da PNEEPEI (BRASIL, 2008) em municípios brasileiros, algumas críticas foram tecidas. Rosalba Garcia (2009) assinala que a ausência de planejamento conjunto da equipe responsável pela inserção das proposições inclusivas junto aos estudantes pode acarretar que decisões sejam centralizadas.

O modo como tais decisões chegam até os docentes, articuladas em um discurso político que as dilui em conteúdo 'acima de qualquer suspeita', contribui para uma adesão acrítica a uma proposta hegemônica, enfraquecendo as condições favoráveis a um trabalho coletivo nas escolas. (GARCIA, 2009, p. 135, grifo do autor).

Destacando o esforço das redes de ensino para efetivar as políticas inclusivas, como a ampliação do atendimento educacional especializado para alunos com deficiência, Garcia (2009) critica a forma pouco politizada como estas operações ocorreram, e desta maneira o trabalho pedagógico direcionado para estudantes com deficiência refletia a despolitização na medida em que se fixam em sobreposição de programas e se desvinculam da educação básica. Para essa autora, outra característica que desvirtua a orientação inclusiva seria o modelo de formação docente ao promover o distanciamento entre os professores do ensino fundamental e os professores com formação no ensino especializado, pois, ao direcionar privilégios para os últimos, contribuem para a manutenção dos saberes sobre os alunos público-alvo da política inclusiva e, consequentemente, reforçam visões e concepções organicistas sobre este público.

Com objetivos semelhantes ao do estudo acima relatado, Rebelo e Kassar (2014) abordaram a política inclusiva e seus efeitos na efetivação do processo ensino- aprendizagem de alunos com deficiência em um município brasileiro. Suas conclusões, elaboradas com base em dados estatísticos disponibilizados pelo Instituto Nacional de Estudos e Pesquisas Educacionais Anísio Teixeira (INEP), dizem que maior contingente dos alunos com deficiência estavam matriculados nos primeiros anos de escolaridade, e desta forma refletem que a progressão escolar não ocorria. Por outro lado, constatou-se o crescimento de matrículas em instituições especiais da região. Destacamos um dos pontos conclusivos apontados:

Nessa análise, concluiu-se que a partir do $1^{\circ}$ ano passa a ser rara a existência de histórias escolares sem algumas reprovações ou desistências. [...] Este é um aspecto relevante a ser ponderado quando se almeja a escolarização de alunos com deficiência em graus mais altos de escolaridade. (REBELO; KASSAR, 2014, p. 17).

A partir das críticas expostas, podemos constatar que a construção de formas que possibilitem o "estar juntos na escola" não pode prescindir de uma operação que considere os sujeitos envolvidos com o fazer do trabalho educativo e, consequentemente, a análise das práticas educativas com vistas a ultrapassar concepções cristalizadas sobre aprendizagem das crianças. Neste sentido destacamos a importância de experiências formadoras para professores que não os considerem multiplicadores (posição esta que nos leva a pensar numa condição de rápidos disseminadores) de 
preceitos e determinações numa lógica quantitativa que, ao embargar possíveis retomadas de posições no trabalho educativo, exige deles a obediência aos ditames da lei. Como assinalam Moschen, Vasques e Frölich (2015), ao narrarem sobre curso de formação de professores estendido ao longo de três anos, onde a escrita e a leitura ocuparam posição principal como aposta que professores alcançassem uma posição enunciativa em suas práticas educativas:

Nossa proposta de trabalho, ao contrário, aposta no tempo como ingrediente necessário á constituição de um diálogo que, no curso em questão, desdobrou-se por meio da escrita dos professores endereçada a leitores atentos aos modos singulares com que os impasses da educação de crianças, tidas como transtorno global de desenvolvimento (TGD), inscreviam na vida desses docentes e das escolas em que atuavam. (MOSCHEN; VASQUES; FRÖLICH, 2015, p. 18).

O Atendimento Educacional Especializado (AEE) em sua configuração disposta na PNEEPEI (2008) como dispositivo realizador da educação especial e que perpassa todos os níveis de aprendizagem confere ao mesmo uma posição centralizada conduzindo a efetivação da Política à sua operacionalização (RAHME; FERREIRA; NEVES, 2019). Outro aspecto presente na caracterização do AEE, como modalidade de ensino realizado nas salas de recursos, diz respeito às suas atividades quando acentua que estas "diferenciam-se daquelas realizadas em sala de aula comum, não sendo substitutas à escolarização" (BRASIL, 2008, p. 11). Dizer que o AEE é uma modalidade de educação especial dentro da própria instituição escolar e não franquear aos professores espaços e condições profissionais que os permitam mudança de posição - é deixá-los a sós - com os argumentos e preceitos do modelo médico para conduzir suas práticas; é repetir a ideia do exercício ancorado na cronometria da aula - é distancia-los, quase que de forma irredutível de um tempo outro que alarga o horizonte, suspendendo a métrica - e subverte a escuridão - é impossibilitá-los de pensar, junto aos seus pares, que o aprender pode seguir vias que interrogam o congelamento de concepções oficiais. Quem mais que os próprios educadores poderiam descobrir, inventar e testemunhar práticas inesperadas de aprendizagem com as ditas "crianças da inclusão" em meio às demais do que aqueles que, com elas, partilham o espaço escolar? A diferenciação de espaços físicos, a condição de modalidade especial e o distanciamento entre os professores envolvidos com a vida escolar das crianças em situação de deficiência parecem mais responder à manutenção de fissuras do que acenar para possibilidades educativas.

Salientamos os efeitos das dificuldades e impasses vividos pelos professores diante das crianças que sofrem em sua experiência de aprendizagem (GIRALDI, 2009), uma vez que não contam com ferramentas conceituais que lhes permitam inventar subversões à fixidez da organização escolar. Assim "desaparelhados", reagem na maioria das vezes de modo inverso a suas funções, ativando o insucesso das crianças nas atividades escolares, ou seja, inscrevendo suas ações no campo das impossibilidades de compreender a gramática escolar. 0 discurso das incapacidades emerge em outras vestimentas e, consequentemente, não há apostas (LAJONQUIÈRE, 1999). As crianças, ao se sentirem apartadas do trabalho escolar, hesitam na busca pelo lugar de "alunos". Perla Zelmanovich (2007, p. 2) diz que a aposta na relação educativa apresenta uma afinidade com o estabelecimento da confiança, "é uma aposta, uma confiança de que algo de bom possa acontecer, ainda que não tenhamos a certeza". Permanecer à parte da sociabilidade inerente às instituições escolares pode conduzir essas crianças para a uma dimensão segregadora, negando-lhes a escola como um ponto de referência. Esta posição apartada das relações educativas impossibilita a entrada na cadeia de transmissões, como ressalta Lajonquière (2010, p. 149): “[...] para que uma educação venha a posteriori se revelar possível - a despeito da impossibilidade da educação - é necessário que o adulto em posição de mestre ensine, mos- 
tre os signos, ao tempo que denegue a própria demanda educativa."

A dimensão do tempo das políticas inclusivas no discurso político-educativo no nosso país tem seus desdobramentos, e como não poderia deixar de ser, reclama pelo amplo debate; discussões que deveriam ocupar as instituições educativas sem a urgência da mudança. Encurtar a letra da lei e remeter para espaços historicamente segregadores não traduzem anseios democráticos, e desta maneira não podem ser considerados um empreendimento político. Não ignorando tais premissas, enfim, remetemo-nos a Freud (2018) ao pensar o trabalho de análise, e consideramos a educação inclusiva como uma operação: a operação da Educação.

\section{Considerações finais}

A chegada de uma criança à escola é um acontecimento que não deveria ser minimizado. Seu enlace com a educação é tributário deste ponto de partida. Frequentar uma escola e experimentar o lugar de aluno provoca mudanças subjetivas que exponenciam seu trânsito simbólico: desloca a criança de uma posição antes restrita à de filho no mesmo movimento em que amplia seu universo ao ser convocada a responder ao Outro social. Para as crianças em situação de deficiência, este acontecimento, quando bem-sucedido, ganha contornos maiores. Todavia suas possibilidades de um percurso escolar são comumente ameaçadas pela dimensão explícita das incapacidades e pela insistência na tradição empirista do exercício da repetição. A monotonia e a improdutividade das tarefas a elas propostas nada dizem do ato educativo. Os possíveis sentidos das reações adversas das crianças a tais procedimentos pedagógicos tendem a ser ignorados pelos professores, descartando a possibilidade que "isso"4 diga da demanda educativa. Anulandose tais manifestações, abole-se a chance de nelas encontrar o que poderia comprometer

4 Forma grafada por Lajonquière (2013) ao se referir ao assujeitamento da criança a uma tradição quando convocada pelos professores a aprender. a criança numa relação de confiança, no ato educativo.

Problematizamos a invisibilidade do trabalho das crianças em situação de deficiência que se faz presente nas escolas inclusivas. A ideia de que com essas crianças o "trabalho não acontece" orienta representações sobre a impossibilidade da oferta do lugar de aluno. Entretanto gostaríamos de ressaltar que, a despeito do rótulo de impróprias que ganham imediatamente, as possíveis ações/respostas faladas e explicitadas pelas crianças com deficiência denotam um trabalho que, talvez, se mostre em modalidades de expressão que não se encaixam precisamente no enquadre que os despreza. Há necessariamente que se fazer furos nas expectativas imaginárias aprendendo a olhar e a ouvir por outros ângulos - para que algo de reconhecimento seja transmitido -, isto que possa ser nomeado como "especial", como distintivo da espera pela resposta correta. Apostamos que assim a escola, enquanto reunião presencial e organizada dos que transmitem saberes e daqueles para quem se transmite, poderá se construir como uma escola para todos.

\section{REFERÊNCIAS}

AINSCOW, Mel. Tornar a educação inclusiva: como esta tarefa deve ser conceituada? In: FÁVERO, Osmar. Et al (org.). Tornar a educação inclusiva. Brasília, DF: UNESCO, 2009. p. 11-24. Disponível em: http://bibliotecadigital.puc-campinas.edu. br/services/e-books/184683por.pdf. Acesso em: 30 jun. 2020.

ASSIS, Machado. Contos de Machado de Assis. São Paulo: Melhoramentos, 2012.

BAQUERO, Ricardo; DIKER, Gabriela; FRIGERIO, Graciela (org.). Las formas de lo escolar. Buenos Aires: Del Estante Editorial, 2007.

BARRÈRE, Anne; SEMBEL, Nicolas. Sociologia da Escola. São Paulo: Loyola, 2006.

BECCHI, E. Le XIX Siècle. In: Histoire de l'enfance en Occident. 2. Du XVIII siècle à nos jours. Paris: Éditions du Seuil, 1998.

BINET, Alfred; SIMON, Théodore. Les enfants 
anormaux. Paris: Privat Éditeur, 1907.

BINET, Alfred; SIMON, Théodore. Les idées modernes sur les enfants. Paris: Ernest Flammarion, 1909.

BORBA, Francisco S. (org.). Dicionário UNESP do Português Contemporâneo. São Paulo: EdUNESP, 2004.

BRASIL. Ministério da Educação. Secretaria de Educação Especial. Política Nacional de Educação Especial na Perspectiva da Educação Inclusiva (PNEEPEI). Brasília, DF: MEC/SEESP, 2008.

CAMBI, Franco. História da Pedagogia. São Paulo: Editora UNESP, 1999.

CANÁRIO, Rui. o que é a escola? Um olhar sociológico. Porto: Porto Editora, 2005.

CANÁRIO, Rui. A escola: das "promessas às incertezas". Educação Unisinos, v. 12, n. 2, p. 72-81, maio/ago. 2008. Disponível em: http:// revistas.unisinos.br/index.php/educacao/article/ view/5309. Acesso em: 15 jul. 2020.

CAVALLARI, Juliana. Efeitos de verdade que emanam do discurso da inclusão e suas implicações subjetivas. In: UYENO, E.; CAVALLARI, J.; MASCIA, $M$. (org.). Mal-estar na inclusão. Campinas, SP: Mercado das Letras, 2014.

FÁVERO, Osmar; FERREIRA, Windyz. Tornar a educação inclusiva. Brasília, DF: UNESCO, 2009. Disponível em: http://bibliotecadigital.puccampinas.edu.br/services/e-books/184683por. pdf. Acesso em: 25 jul. 2020.

FERREIRA, Carla Mercês Rocha Jatobá; LOPES, Tatiane Felipe. A escola e a educação inclusiva: professoras e alunos em cena. Revista Educação Especial, v. 29, n. 55, p. 441-456, maio/ago. 2016. FREITAS, Marcos. 0 aluno-problema: forma social, ética e inclusão. São Paulo: Cortez, 2011.

FREITAS, Marcos; BICCAS, Maurilane. História social da educação no Brasil (1926-1996). São Paulo: Cortez, 2009.

FREUD, Sigmund. 0 futuro de uma ilusão. In: FREUD, Sigmund. Obras Completas de Sigmund Freud (volume 17): inibição, sintoma e angústia, o futuro de uma ilusão e outros textos. Tradução de Paulo César de Souza. 1. ed. São Paulo: Companhia das Letras, 2014. p. 231-301.

FREUD, Sigmund. 0 mal-estar na civilização. In: FREUD, Sigmund. Obras Completas de Sigmund Freud (volume 18): o mal-estar na civilização, novas conferências introdutórias à psicanálise e outros textos. Tradução de Paulo César de Souza. 1. ed. São Paulo: Companhia das Letras, 2010. p. 13-122.

FREUD, Sigmund. Construções na análise. In: FREUD, Sigmund. Obras Completas de Sigmund Freud (volume 19): Moisés e o monoteísmo, compêndio de psicanálise e outros textos. Tradução de Paulo César de Souza. 1. ed. São Paulo: Companhia das Letras, 2018. p. 327-344.

GARCIA, Rosalba. Política de educação inclusiva e trabalho pedagógico: uma análise do modelo de educação especial na educação básica. In: BAPTISTA, Claudio Roberto; JESUS, Denise (org.). Avanços em políticas de inclusão. 0 contexto da educação especial no Brasil e em outros países. Porto Alegre: Mediação, 2009. p. 123-138.

GIRALDI, Graciela. El fracaso escolar. In: DAUMAS, Alejandro; STIGLITZ, Gustavo (comp.). Psicoanálisis con niños y adolescentes 2 . Políticas, prácticas y saberes sobre el niño. Buenos Aires: Grama Ediciones, 2009. p. 113-115.

HUGON, Marie-Anne; GATEAUX, Jacqueline; VIAL, Monique. Les enfants des classes de perfectionnement (1907-1950). In: CRESAS: Intégration ou marginalization? Aspects de l'éducation spécialisé. Paris: INRP/L'Harmattan, 1984. p. 77-104.

INSTITUTO ANTONIO HOUAISS. Dicionário Houaiss da Língua Portuguesa. Rio de Janeiro: Instituto Antônio Houaiss de Lexicografia/Objetiva, 2012.

JANNUZZI, Gilberta de Martino. A educação do deficiente no Brasil: dos primórdios ao início do século XXI. 2. ed. Campinas, SP: Autores Associados, 2006.

LAJONQUIÈRE, Leandro. Infância e ilusão (psico) pedagógica. Petrópolis, RJ: Vozes, 1999.

LAJONQUIÈRE, Leandro. Figuras do infantil. A psicanálise na vida cotidiana com as crianças. Petrópolis, RJ: Vozes, 2010.

LAJONQUIÈRE, Leandro. A palavra e as condições da educação escolar. Educação e Realidade, Porto Alegre, v. 38, n. 2. p. 455-469, abr./jun. 2013. Disponível em: https://seer.ufrgs.br/ educacaoerealidade/article/view/34257. Acesso em: 14 jul. 2020.

LELIÈVRE, Claude. Histoire des institutions scolaires. Paris: Nathan Pédagogie, 1991. 
MANACORDA, Mario Alighiero. História da Educação da antiguidade aos nossos dias. São Paulo: Cortez, 1996.

MAULINI, Olivier; PERRENOUD, Philippe. La forme scolaire de l'éducation de base:tensions internes et évolutions. In: MAULINI, O.; MONTANDON, C. (org.). Les formes de l'éducation: variété et variations. Bruxelles: De Boeck, 2005. p. 147-168.

MAZZOTTA, Marcos José. Educação especial no Brasil: história e políticas públicas. São Paulo: Cortez, 2005.

MENDES, Eniceia. Breve histórico da educação especial no Brasil. Revista Educacion y Pedagogia, Medellín, Colômbia, n. 57, v. 22, p. 93-109, mayo/ ago. 2010.

MILNER, Jean-Claude. De l'école. Paris: Verdier Poche, 2009.

MOSCHEN, Simone; VASQUES, Carla; FRÖLICH, Cláudia. Psicanálise, educação especial e formação de professores: construções em rasuras. In: VASQUES, Carla; MOSCHEN, Simone (org.). Psicanálise, educação especial e formação de professores: construções em rasuras. Porto Alegre: Evangraf, 2015. p. 11-28.

MUEL, Francine. L'école obligatoire et l'invention de l'enfance anormale. Actes de la Recherche em Sciences Sociales, Paris, n. 1, p. 60-74, 1975.

NASCENTES, Antenor. Dicionário Etimológico da Língua Portuguesa. Rio de Janeiro: Livraria Francisco Alves, 1955.

NASCIMENTO, Maria Isabel. Et al (org.). Instituições escolares no Brasil: conceito e reconstrução histórica. Campinas, SP: Autores Associados, 2007.

NEVES, Libéria Rodrigues; RAHME, Mônica Maria Farid; FERREIRA, Carla Mercês da Rocha Jatobá. Política de educação especial e os desafios de uma perspectiva inclusiva. Educação e Realidade, Porto Alegre, v. 44, n. 1, 2019.

PATTO, Maria Helena. A produção do fracasso escolar. Histórias de submissão e rebeldia. São Paulo: T. A. Queiroz, 1993.

PINELL, Patrice; ZAFIROPOULOS, Markos. Un siècle d'échecs scolaires (1882-1982). Paris: Les editions ouvrières, 1983.

PINTASSILGO, Joaquim. Et al. A história da educa- ção em Portugal. Porto: Asa, 2007.

RAHME, Mônica Maria Farid. Laço social e educação: um estudo sobre os efeitos do encontro com o outro no contexto escolar. Belo Horizonte: Fino Traço, 2014.

RAHME, Mônica Maria Farid; FERREIRA, Carla Mercês da Rocha Jatobá; NEVES, Libéria Rodrigues. Sobre educação, política e singularidade. Educação e Realidade, Porto Alegre, v. 44, n. 1, 2019.

REBELO, Andressa; KASSAR, Mônica. Implantação de programas de educação inclusiva em um município brasileiro: garantia de efetivação do processo ensino-aprendizagem? Arquivos Analíticos de Políticas Educativas, v. 22, n. 1, p. 1-25, 2014. Disponível em: https://dialnet.unirioja.es/ servlet/articulo?codigo $=5650426$. Acesso em: 13 jul. 2020.

Robert, Paul. Le Nouveau Petit Robert. Dictionnaire de la Langue Française. Paris: Dictionnaires Le Robert, 1996.

SAVIANI, Dermeval. Instituições escolares: conceito, história, historiografia e práticas. Cadernos de História da Educação, n. 4, p. 27-33, jan/dez. 2005. Disponível em: http://www.seer.ufu.br/index. $\mathrm{php} / \mathrm{che} /$ article/view/382/363. Acesso em: 13 jul. 2020.

SOUZA, Maria Cecília de. À sombra do fracasso escolar: a psicologia e as práticas pedagógicas. Estilos da Clínica, v. 3, n. 5, p. 63-83, 1998.

THOMAZET, Serge; MERINI, Corine. L'école inclusive comme objet frontière. La nouvelle revue de l'adaptation et de la scolarisation, n. 70, p. 1-12, 2015. Disponível em: https://www.researchgate. net/publication/310329360_L\%27ecole_ inclusive_comme_objet_frontiere. Acesso em: 15 jul. 2020.

VINCENT, Guy; LAHIRE, Bernard; THIN, Daniel. Sobre a história e a teoria da forma escolar. Educação em Revista, Belo Horizonte, n. 33, p. 7-47, jun/2001.

ZELMANOVICH, Perla. Apostar a la transmisión y a la enseñanza. A propósito de la producción de infâncias. Ushuaia, Argentina: Ministerio de Educación, Ciencia y Tecnologia, 2007.

Recebido em: 15/08/2020 Aprovado em: 06/12/2020

(cc) EY-NC Este é um artigo publicado em acesso aberto sob uma licença Creative Commons. 